\title{
Elektrolitik Yöntemle Sert Krom Kaplanan Yapı Çeliğinde Kaplama Parametrelerinin Taguchi Metodu ile Optimizasyonu
}

\author{
Optimization of Coating Parameters in Hard Chrome Coated Structural Steel by \\ Electrolytic Method with Taguchi Method
}

\author{
Hasan KIR $^{1, a}$, Serkan APAY ${ }^{* 2, b}$

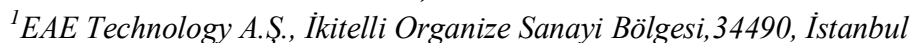 \\ ${ }^{2}$ Düzce Üniversitesi, Teknoloji Fakültesi, Makine ve İmalat Mühendisliği Bölümü, 81620, Düzce
}

\begin{tabular}{|c|c|c|}
\hline - Geliş tarihi / Received: 14.03 .2019 & - Düzeltilerek geliş tarihi / Received in revised form: 17.09.2019 & - Kabul tarihi / Accepted: 23.09.2019 \\
\hline
\end{tabular}

\begin{abstract}
$\ddot{O} z$
Sert krom kaplama, metallere aşınma direnci, korozyon direnci ve dekoratif görüntü kazandırmak amacıyla yapılan bir yüzey kaplama işlemidir. Kaplama işlemi metallere birçok farklı kaplama metodu ile uygulanabilmektedir. Bunlar; kimyasal buhar biriktirme (CVD), fiziksel buhar biriktirme (PVD), diğer plazma kaplama yöntemleri, yüksek hızda oksi-yakıt püskürtme (HVOF) ve elektrolitik kaplama yöntemleridir. Elektrolitik sert krom kaplamada kaplama parametreleri büyük önem taşımaktadır. Akım yoğunluğu, elektrolitik banyo sıcaklığı, anot katot arası mesafe, banyo pH oranı ve kaplama süresi önemli parametrelerdir. Bu çalışmada, yapı çeliğinin sertlik özelliklerine, elektrolitik yöntemle sert krom kaplama parametrelerinden akım yoğunluğu, banyo sıcaklığı ve anot katot mesafe değerleri incelenmiş ve optimum sertlik değerleri tespit edilmiştir. Taguchi $\mathrm{L}_{18}$ ortagonal dizin sıralamasına göre uygulanmış deneysel çalışma sonucunun değerlendirilmesinde Sinyal/Gürültü $(\mathrm{S} / \mathrm{N})$ oranı temel alınmıştır. Kontrol faktörlerinin sonuçlara etkisi Varyans analizi (ANOVA) kullanılarak hesaplanmıştır. Sonuç olarak, Taguchi yöntemi ile hesaplanan optimizasyon değerleri ile deneysel çalışmada kullanılan aynı değerlerde en yüksek sertlik değerine ulaşıldığı görülmüştür.
\end{abstract}

Anahtar kelimeler: Elektrolitik Yöntem, Sertlik, Sert Krom Kaplama, Taguchi Metodu

\begin{abstract}
Hard chrome plating is a surface coating process to give metals wear resistance, corrosion resistance and decorative appearance. The coating process can be applied to metals with many different coating methods. These; chemical vapor deposition (CVD), physical vapor deposition (PVD), other plasma coating methods, high-speed oxy-fuel injection (HVOF) and electrolytic coating methods. Plating parameters are very important in electrolytic hard chromium plating. Current density, electrolytic bath temperature, distance between anode cathode, bath $\mathrm{pH}$ ratio and coating time are important parameters. In this study, hardness properties of structural steel, current density, bath temperature and anode-cathode distance values of hard chrome plating parameters were investigated by electrolytic method and optimum hardness values were determined. Signal/Noise $(S / N)$ ratio was used in the evaluation of Taguchi $L_{18}$ orthogonal sequence. The effect of control factors on the results was calculated using Variance Analysis (ANOVA). As a result, it was observed that optimization values calculated with Taguchi method and highest hardness values were reached in the same values used in the experimental study.
\end{abstract}

Keywords: Electrolytic Method, Hardness, Hard Chrome Plating, Taguchi Method

\footnotetext{
*berkan APAY; serkanapay @ duzce.edu.tr, Tel: (0380) 54211 33/2252, orcid.org/0000-0003-4624-9082

a orcid.org/0000-0001-5526-8467
} 


\section{Giriş}

Makine imalat endüstrisinde çelik malzemeler sahip oldukları özelliklerden dolayı yoğun olarak tercih edilmektedir. $\mathrm{Bu}$ malzemeler ya sahip olduğu mekanik özelliklerle ya da mekanik özellikleri iyileştirme sonrasında makine parçası olarak kullanılmaktadırlar. Mekanik özelliklerin değiştirilmesi sertlik, aşınma ve korozyon direncinin iyileştirilmesi olarak gerçekleştirilmektedir. İyileştirme işlemleri yüzey işlemleri olarak da bilinen kaplama yöntemleri ile yapılmaktadır. Bazı durumlarda yüzey özelliklerinin iyileştirilmesi 1sıl işlemler ile yapılmaktadır. Hem isıl işlemlerde hem de yüzey kaplamalarında amaç imalatı yapılacak parçanın çalışacağı ortama uygun hale getirilmesi amaçlanmaktadır. Dekoratif amaçlı olarak yapılan kaplamalarda bulunmaktadır (Saraç, 1995; Perianu, 2016). Kaplama işlemleri, kimyasal çöktürme yöntemleri (PVD ve CVD), termal yöntemler (Plazma kaplama, HVOF vb.) ve sicak daldirma ve elektrolitik olarak uygulanmaktadır (Lausmann, 1996; Bozyaz1 vd., 2004; Bolelli vd., 2006). Kimyasal ve termal kaplama yöntemleri ile kıyaslandığında elektrolitik kaplama yöntemi daha ekonomiktir (Borisenko vd., 2017).

Elektrolitik kaplama yöntemlerinden sert krom kaplama, makine parçaları, otomotiv araç gereçleri ve takım malzemelerinin ve aşınma karakteristiklerini iyileştirmek için kullanılmaktadır (Browning, 1994; Chen vd., 1996; Rebholz vd., 1999). Aşınma, makine parçalarında ve birbirleri ile temas halinde çalışan otomobil parçalarında yüzeylerde oluşan, malzeme kaybı olarak görülen bir problemdir (Lindsay, 1999; Schlesinger vd., 2014). Yeterli yağlamanın olmadığ 1 durumlarda, motor parçalarında bu aşınma türleri sıkça görülebilmektedir (İpek vd., 2006). Şekil 1 'de yeterli yağlama olmadığı için aşınan turbo şarj mili görülmektedir. Turbo şarj mili gibi çeliklerde, geleneksel yöntemleri (1sıl işlemler vb. yöntemler) ile aşınma direnci kazandırılmaya çalışıldığında parçalarda boyut toleranslarını kaybolması ve istenen yeterlilikte sertlik değerlerine ulaşılamaması gibi sorunlar ortaya çıkacaktır (Kahraman vd., 2013). Aşınan parçalarla ilgili olarak malzemenin tokluk ve sertlik gibi mekanik değerleri önemli unsurladır (Doubek vd., 2011; Demirsöz vd., 2018).

Aşınma problemini en aza indirmek için genellikle uygulanan işlem aşınan yüzeyi, aşınmaya karşı dirençli hale getirmektir. Elektrolitik sert krom kaplama yapılan önceki çalışmalarda, numunelerde artan yüzey sertliği ile aşınma direncinin de arttığı görülmüştür (Fedrizzi vd., 2002). Barbato ve arkadaşları yaptıkları çalışmada, elektrolitik sert krom kaplanan 1045 çelik malzemede sertliğin arttığını görmüşlerdir (Salvador Barbato vd., 2008). Karuppasamy ve arkadaşları, 50CrMo4 şaft mili üzerine yapmış oldukları sert krom kaplama ile aşınma direncinin ve sertlik değerlerinin arttığını tespit etmişlerdir (Karuppasamy vd., 2018). Almotairi ve arkadaşları, 416 kalite paslanmaz çelik mil üzerine sert krom kaplama yapmışlar ve milin korozyon direnci ile aşınma direncinde artış olduğunu görmüşlerdir (Almotairi vd., 2016).

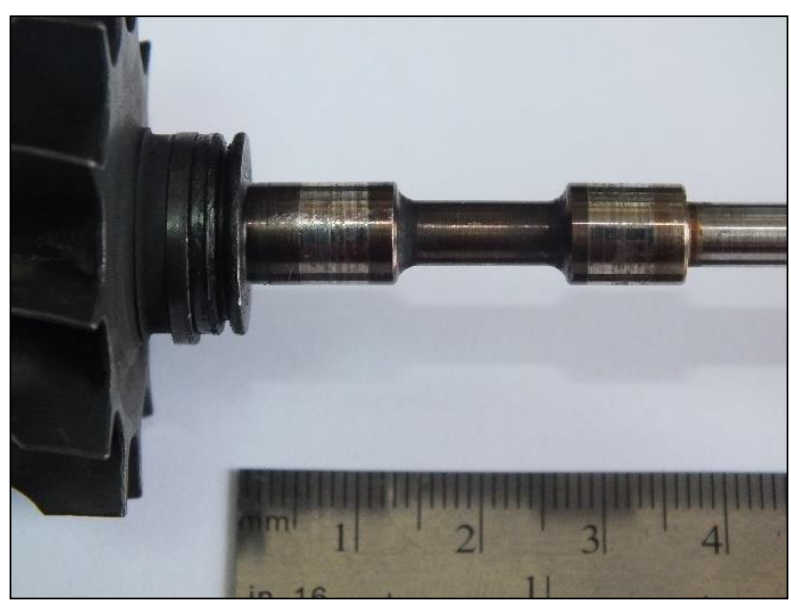

Şekil 1. Yetersiz yağlama sonucu aşınmış turbo şarj mili

Bir ürün geliştirme işlemlerinde ön deneysel çalışmalar yapmak, üretim esnasındaki birçok problemi önceden görüp önlemini alma ve ürün kalitesini daha iyi hale getirmek için yapılmaktadır. Deneysel çalışmaları gerçekleştirmek için iyi bir deney tasarımına ihtiyaç duyulmaktadır. Bazı çalışmalarda deneysel parametrelerin çokluğu çalışma maliyetlerinde ciddi artışlara da neden olmaktadır. Bu maliyetler, Genichi Taguchi tarafindan geliştirilen ortagonal dizileriyle birçok parametre içeren deneylerde kullanılan Taguchi yöntemi, daha az deneme ile daha iyi neticeler elde ederek azaltılmıştır (Gür vd., 2017). Taguchi yönteminin amac1, kontrol edilebilen değişkenlerin seviyeleri aktif, kontrol edilemeyen değişkenlerin seviyelerini pasif (deney harici) tutarak deneysel prosesler bütünü hazırlamaktır (Gür, 2013). Taguchi yöntemi ile hazırlanan deneysel düzeneklerde birçok deneyi yapmadan sonuçları görmek mümkündür. Ayrıca Taguchi yöntemi ile istenen deneysel sonuçlar, çalışmadaki deneysel parametreler optimize edilerek daha hizlı ve daha az deneme ile elde edilebilmektedir. Taguchi yöntemi, deneysel parametreleri optimize etmek için kullanılan uygun maliyetli ve güçlü bir metottur (Emre, 2015; Y1ldırım vd., 2019). 
$\mathrm{Bu}$ çalışmada, elektrolitik yöntemle sert krom kaplanan yapı çeliğinde kaplama parametrelerinin Taguchi metodu ile optimizasyonu incelenmiştir. Optimizasyon işleminde sertlik değeri "en büyüken iyi" kontrol karakteristiğine göre yapılmıştır. Kaplama parametrelerinin deneysel çalışmada etki değerleri Varyans analizi (ANOVA) kullanılarak saptanmıştır.

\section{Deneysel Çalışmalar}

Elektrolitik yöntemle sert krom kaplanan silindirik numunelerde kaplama parametrelerinin etkisini incelemek için endüstride kolaylıkla bulunan, mekanik özellikleri düşük, $6 \mathrm{~mm}$ çapında yapısal düşük karbonlu mil kullanılmıştır. Mil numuneleri deneysel kaplama işlemine hazırlamak için CNC torna tezgâhı ile Şekil 2'de verilen ölçülere getirilmiştir. $\mathrm{Bu}$ ölçüler otomobillerde kullanılan turbo şarj mili ölçülerine yakındır. Deneylerde kullanılan yapı çeliğine ait kimyasal bileşim Tablo 1'de verilmiştir.

Tablo 1. Yapı çeliğinin kimyasal analizi (\% A

\begin{tabular}{cccccc}
\hline \hline $\mathbf{C}$ & Mn & Si & S & P & Fe \\
\hline \hline 0.11 & 0.66 & 0.19 & 0.033 & 0.028 & Kalan \\
\hline
\end{tabular}

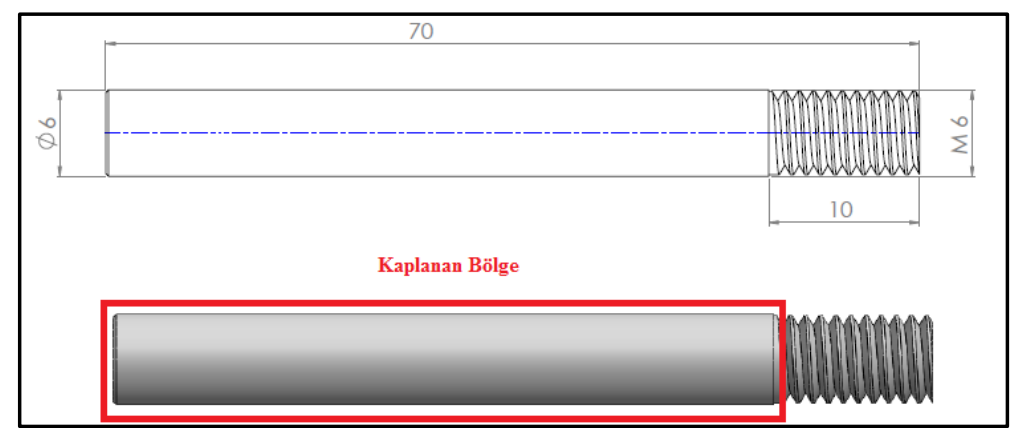

Şekil 2. Elektrolitik sert krom kaplanan numune

Krom kaplama tankı polimerden olup içerisine elektrikli titan muhafazalı 1sıtıcı yerleştirilmiş anot ve katot çubukları için lama kesitli bakır malzeme kullanılmıştır. Anotlarda ise \% 7 kalay, \%93 kurşun uzun şerit malzeme ve güç kaynağ1 olarak Mersan marka 15 volt 300 amperlik redresör kullanılmıştır. Sert krom kaplama banyosuna ait kimyasal değerler; Kromik asit $\left(\mathrm{CrO}_{3}\right) 250 \mathrm{gr} / \mathrm{lt}$ Sülfürik asit $\left(\mathrm{H}_{2} \mathrm{SO}_{4}\right) 25 \mathrm{gr} / \mathrm{lt} \mathrm{gaz}$ kesici 100 cc'lik köpük malzeme şeklindedir.

Elektrolitik sert krom kaplama öncesinde, kaplanacak malzeme, polisajlama işlemiyle üzerindeki pislik ve kirden arındırılıp temiz bir yüzey elde edilmiştir. Polisaj işleminden sonra elektrolitik yă alma işlemi ile yüzeydeki yă kalıntıları temizlenmiştir. Yağ alma işleminden çıkan malzemeler sırayla daldır-çıkar yöntemiyle önce saf suya sonra \% 5 sülfürik asitli suya ve sonrasinda da tekrar saf suya daldırılip kaplama banyosuna girmeye hazır hale getirilmiştir. Numunelerin yă alma temizle işlemlerinde, kaplama öncesi kaplamaya hazırlama işlemlerinde ve sert krom kaplama işlemlerinde Şekil 3'te görülen numune bağlama aparatı kullanılmıştır. Sert krom kaplama işlemlerinde değişken parametre olarak; akım yoğunluğu, anot- katot arası mesafe ve banyo sicaklığı kullanılmıştır.
Numunelerin banyo içinde bekleme süreleri 1 saat olarak, ayrıca banyo $\mathrm{pH}$ değeri 5.1 olarak sabit tutulmuştur.

Deneylerde kullanılan numuneler, kaplama açısından sorun olmayan ve hatasız kaplanmış parçalardan seçilmiş ve tüm deneysel çalışmalar bu numuneler üzerinde gerçekleștirilmiştir. Deneylerde kullanılan parametreler Tablo 2'de verilmiştir. Sert krom kaplama işleminden sonra banyodan çıkan numuneler iki aşamalı su ile yıkama ve su ile durulama aşamasından geçirilerek kurutma işlemine geçilmiştir.

Tablo 2. Deneylerde kullanilan sert krom kaplama parametreleri

\begin{tabular}{ccc}
\hline \hline $\begin{array}{c}\text { Akım Yoğunluğu } \\
\left(\mathbf{A m p} / \mathbf{d m}^{\mathbf{2}}\right)\end{array}$ & $\begin{array}{c}\text { Kaplama Banyo } \\
\text { Sıcaklığı } \\
\left({ }^{\mathbf{0}} \mathbf{C}\right)\end{array}$ & $\begin{array}{c}\text { Anot-Katot } \\
\text { Arası Mesafe } \\
(\mathbf{m m})\end{array}$ \\
\hline \hline 25 & 40 & 100 \\
40 & 50 & 200 \\
55 & 60 & \\
\hline
\end{tabular}

Doğru deney tasarımının kurulması, deneysel çalışmalarda elde edilecek sonuçların doğruluğu için önem arz etmektedir. Elektrolitik yöntemle sert krom kaplamanın gerçekleştirildiği bu çalışmada, deneysel düzenek ve sonuç analiz 
yöntemi olarak Taguchi $\mathrm{L}_{18}$ ortagonal dizin kullanılmıştır. $\mathrm{Bu}$ yaklaşımda, sonuçları analiz edebilmek için Sinyal/Gürültü (S/N) oranı olarak bilinen bir istatistiksel performans ölçüsü kullanılmaktadır. Bu orandaki "S" Sinyal oranını, " $\mathrm{N}$ " ise gürültü oranını ifade etmektedir.

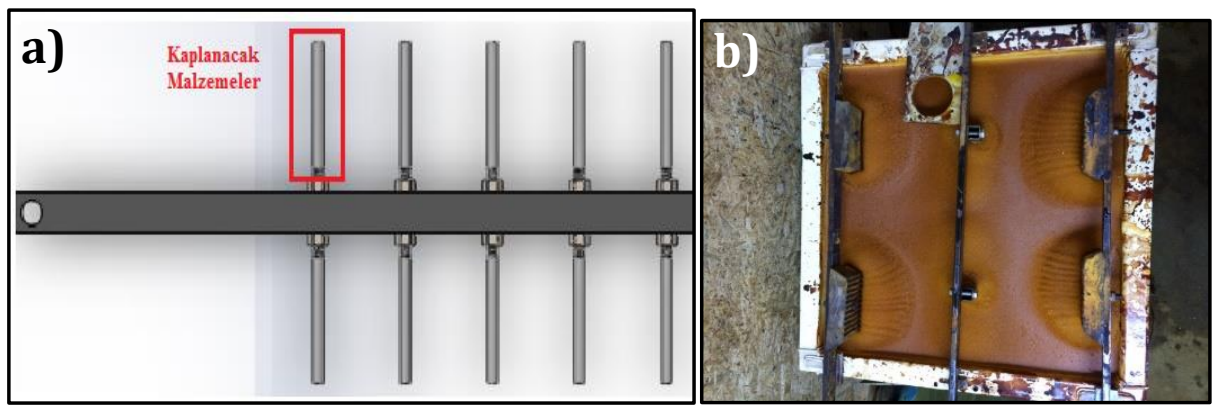

Şekil 3. a) Numune bağlantı aparatı ve b) kaplama banyosu

Deney sonucuna etki eden oranlardan, sinyal oranı sistemde gerçek değeri, gürültü oranı ise deney düzeneğine katılamayan fakat deney sonucuna etki eden oranları tanımlamaktadır. Gürültü kaynakları, elde edilmek istenen performans karakteristiklerinin hedef değerden sapmasına sebep olan tüm değişkenlerdir (Kara vd., 2017). $\mathrm{S} / \mathrm{N}$ oranlarının hesaplanmasında karakteristik tipine bağlı nominal en iyi, en büyük en iyi ve en küçük en iyi metotları kullanılmaktadır (Masmiati vd., 2015). Bu çalışma, kalite karakteristiği olarak ele alınan kaplama sertlik değerinin yüksek olması arzu edildiğinden $\mathrm{S} / \mathrm{N}$ oranlarının hesaplanmasında "en büyük en iyi" yaklaşımı dikkate alınmıştır. S/N oranlarının hesaplanmasında eşitlik 1'de verilen denklem kullanılmıştır. Burada; " $y$ " ölçülen sertlik değerini, " $i ”$ gözlem değerini, " $n$ " bu çalışma için geçerli deneyleri ifade etmektedir.

$\frac{S}{N}=-10 \log \left(\frac{1}{n} \sum_{i=1}^{n} \frac{1}{y_{i}^{2}}\right)$

Yapısal çeliğin elektrolitik yöntemle yapılan sert krom kaplanmasinda kontrol faktörleri ve seviyeleri Tablo 3'de verilmiştir.

Tablo 3. Kontrol faktörleri ve seviyeleri

\begin{tabular}{ccccc}
\hline \hline Sembol & $\begin{array}{c}\text { Kontrol } \\
\text { Faktörleri }\end{array}$ & $\begin{array}{c}\text { Seviye } \\
\mathbf{1}\end{array}$ & $\begin{array}{c}\text { Seviye } \\
\mathbf{2}\end{array}$ & $\begin{array}{c}\text { Seviye } \\
\mathbf{3}\end{array}$ \\
\hline \hline A & $\begin{array}{c}\text { Anot Katot } \\
\text { Mesafesi (mm) }\end{array}$ & 100 & 200 & - \\
\hline B & $\begin{array}{c}\text { Akım } \\
\text { Yoğunluğu } \\
\left(\text { Amp/dm }{ }^{2}\right)\end{array}$ & 25 & 40 & 55 \\
C & $\begin{array}{c}\text { Banyo } \\
\text { Sicaklığ }\left({ }^{\circ} \mathrm{C}\right)\end{array}$ & 40 & 50 & 60 \\
\hline & & & & \\
\hline
\end{tabular}

\section{Bulgular ve Tartışma}

Deneylerde kullanılan yapı çeliğine ait mikroyapı görüntüsü Şekil 4'te verilmiştir. Yap1 incelendiğinde, düşük karbonlu çeliklerde görülen ferrit + sementit yapıdan oluştuğu görülmektedir.

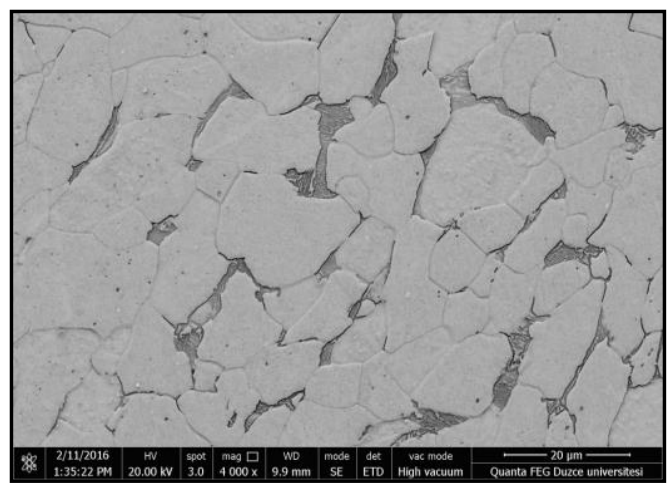

Şekil 4. Yapı çeliği malzemesi içyapısı

Mikro yapılarda kaplama bölgesinde oluşan mikro çatlaklara ait görüntüler ise Şekil 5'de verilmiştir. Yapılan literatür çalışmaları göstermiştir ki sert krom kaplama yapılan numunelerde kaplama bölgesinde mikro çatlaklar oluşmaktadır. $\mathrm{Bu}$ çatlak oluşumunun başlıca nedeni kaplama işlemi sonrasında meydana gelen, kaplamada ani sertlik artışıdır. Bu neden benzer çalışmalardaki bulgular ile paralellik göstermektedir.

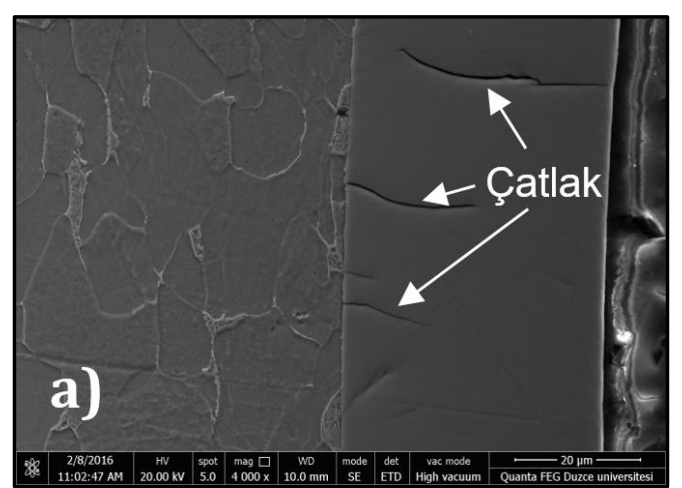

Şekil 5. Numunelere ait mikro çatlak görüntüsü 


\subsection{Sertlik Optimizasyonu}

Yapısal düşük karbonlu çeliğe elektrolitik yöntemle yapılan sert krom kaplama işleminin
Taguchi $\mathrm{L}_{18}$ deneysel tasarımına göre gerçekleştirilen optimizasyon deneyi sertlik ve aşınma sonuçları ve hesaplanan $\mathrm{S} / \mathrm{N}$ oranları tahmin değerleri Tablo 4'de verilmiştir.

Tablo 4. Deney tasarımı, sertlik ve $\mathrm{S} / \mathrm{N}$ oranları

\begin{tabular}{|c|c|c|c|c|c|c|}
\hline No & $\begin{array}{c}\text { (A) } \\
\text { Anot Katot } \\
\text { Mesafesi } \\
(\mathbf{m m})\end{array}$ & $\begin{array}{c}\text { (B) } \\
\text { Akım } \\
\text { Yoğunluğu } \\
(\text { Amp/dm²) }\end{array}$ & $\begin{array}{c}(\mathbf{C}) \\
\text { Banyo } \\
\text { Sicakllğg } \\
\left({ }^{\circ} \mathbf{C}\right)\end{array}$ & $\begin{array}{l}\text { Sertlik } \\
\left(\mathbf{H V}_{0.1}\right)\end{array}$ & $\begin{array}{c}\text { S/N Oranı } \\
\text { (dB) }\end{array}$ & $\begin{array}{l}\text { Tahmin Edilen } \\
\text { Sertlik Değeri } \\
\left(\mathrm{HV}_{0.1}\right)\end{array}$ \\
\hline 1. & $\overline{c 100}$ & 25 & 40 & $\begin{array}{l}743.0 \\
\end{array}$ & 57.4198 & 743.01 \\
\hline 2. & 100 & 25 & 50 & 751.6 & 57.5197 & 752.01 \\
\hline 3. & 100 & 25 & 60 & 765.1 & 57.6744 & 764.66 \\
\hline 4. & 100 & 40 & 40 & 860.2 & 58.6920 & 862.21 \\
\hline 5. & 100 & 40 & 50 & 869.5 & 58.7854 & 871.21 \\
\hline 6. & 100 & 40 & 60 & 887.6 & 58.9643 & 883.86 \\
\hline 7. & 100 & 55 & 40 & 789.2 & 57.9437 & 785.95 \\
\hline 8. & 100 & 55 & 50 & 797.3 & 58.0324 & 794.95 \\
\hline 9. & 100 & 55 & 60 & 802.0 & 58.0835 & 807.60 \\
\hline 10. & 200 & 25 & 40 & 738.2 & 57.3635 & 740.11 \\
\hline 11. & 200 & 25 & 50 & 748.8 & 57.4873 & 749.11 \\
\hline 12. & 200 & 25 & 60 & 764.0 & 57.6619 & 761.76 \\
\hline 13. & 200 & 40 & 40 & 855.6 & 58.6454 & 858.85 \\
\hline 14. & 200 & 40 & 50 & 866.7 & 58.7574 & 867.85 \\
\hline 15. & 200 & 40 & 60 & 884.9 & 58.9379 & 880.50 \\
\hline 16. & 200 & 55 & 40 & 788.3 & 57.9338 & 784.35 \\
\hline 17. & 200 & 55 & 50 & 794.6 & 58.0030 & 793.35 \\
\hline 18. & 200 & 55 & 60 & 800.8 & 58.0705 & 806.00 \\
\hline
\end{tabular}

Taguchi metodunda, kalite karakteristiklerine ait optimum faktörler ve bu faktörlere ait seviyelerin belirlenmesinde $\mathrm{S} / \mathrm{N}$ yanit tablosu kullanılmakta olup sertlik üzerinde her kontrol faktörünün etkisini gösteren $\mathrm{S} / \mathrm{N}$ yanıt tablosu Tablo 5'de verilmiştir. Tablodaki $\mathrm{S} / \mathrm{N}$ içerisindeki en yüksek değer o faktöre ait optimum seviyeyi göstermektedir.

Tablo 5. Deney tasarımı, sertlik ve $\mathrm{S} / \mathrm{N}$ oranları

\begin{tabular}{cccc}
\hline \hline Seviye & $\begin{array}{c}\text { (A)Anot } \\
\text { Katot } \\
\text { Mesafesi } \\
(\mathbf{m m})\end{array}$ & $\begin{array}{c}\text { (B) Akım } \\
\text { Yoğunluğu } \\
(\text { Amp/dm }\end{array}$ & $\begin{array}{c}\text { (C) } \\
\text { Banyo } \\
\text { Sicakllğı } \\
\left({ }^{\mathbf{C}} \mathbf{C}\right)\end{array}$ \\
\hline \hline $\mathbf{1}$ & $\mathbf{5 8 . 1 2}$ & 57.52 & 58.00 \\
\hline $\mathbf{2}$ & 58.10 & $\mathbf{5 8 . 8 0}$ & 58.10 \\
\hline $\mathbf{3}$ & - & 58.01 & $\mathbf{5 8 . 2 3}$ \\
\hline Delta & 0.03 & 1.28 & 0.23 \\
\hline Siralama & 3 & 1 & 2 \\
\hline
\end{tabular}

Tablo 5'de verilen değerler dikkate alındığında, optimum kaplama sertliğine ait seviyeleri veren S/N oranları A1B2C3 olmuştur. Diğer bir ifadeyle anot-katot mesafesi, akım yoğunluğu ve banyo sıcaklığı için sırasıyla 58.12 (Seviye 1), 58.80 (Seviye 2) ve 58.23 (Seviye 3) optimum değerler olmuştur. Bu tablo seviye değerleri kullanılarak oluşturulan ana etki grafiği Şekil 6 'da verilmiştir. Deney tasarımı, sertlik ve $\mathrm{S} / \mathrm{N}$ oranları tablosunda (Tablo 4) olduğu gibi Şekil 6'da verilen ana etki grafiğginde de en büyük $\mathrm{S} / \mathrm{N}$ değerleri, kaplamada kullanılan parametrelere ait optimum seviyeleri göstermektedir. Bu değerlere göre elektrolitik sert krom kaplama işleminde, anot-katot mesafesi, akım yoğunluğu ve banyo sıcaklığ için sırasıyla optimum değerler $100 \mathrm{~mm}$ mesafede, 40 amper değerinde ve $60{ }^{\circ} \mathrm{C}$ sıcaklığında yapılan işlem olarak belirlenmiştir.

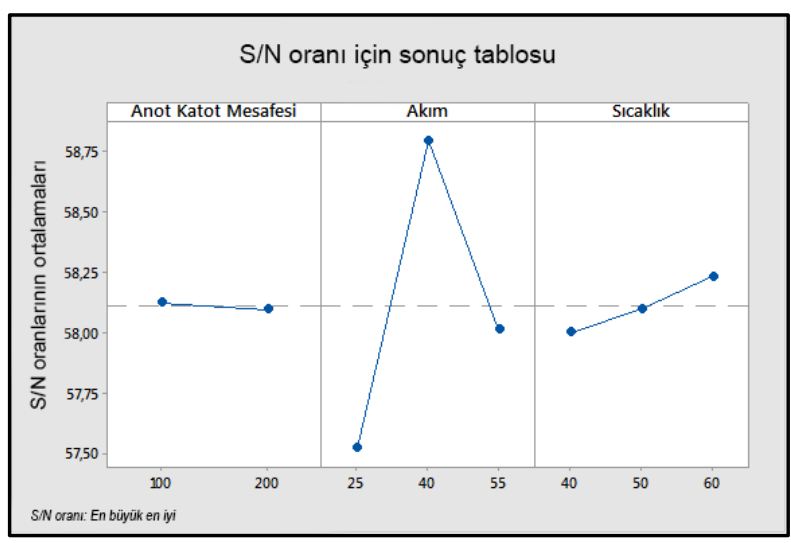

Şekil 6. S/N oranları için ana etki grafiği 


\subsection{Varyans Analizi (ANOVA)}

Bu deneyde kullanılan bütün kontrol faktörlerinin, birbirleri ile olan etkileşimleri, bu faktörlerin performans karakteristiğini ne kadar etkilediği, deneysel çalışmadaki parametreler farklılıkların performans karakterini ne ölçüde değiştirdiği ve bu değişim sebeplerinin belirlenebilmesi için istatiksel Varyans analizi (ANOVA) uygulanmaktadır (Kara vd., 2017). Tablo 6'da, kaplama sertliği üzerine etki eden kontrol faktörlerinin, etki seviyelerini belirlemek amaciyla uygulanan ANOVA sonuçları verilmiştir. Bu tablo üzerinde deneysel çalışmadaki değişkenlerin önem seviyesini gösteren $\mathrm{F}$ değerleri ve katk1 oranları yüzdesi (PCR) görülmektedir. ANOVA işlemi $\% 95$ güvenirlik ve $\% 5$ önem seviyelerinde uygulanmıştır. Deneyde kullanılan kontrol faktörlerin etki düzeylerinin belirlenmesinde, etki değeri en fazla olan $\mathrm{F}$ değeri sonuca en çok etki eden değer olarak belirlenir. $\mathrm{Bu}$ değerin belirlenmesinde $\mathrm{F}$ değeri sonuçları birbirleri ile kıyaslanmaktadır. ANOVA sonuçları incelendiğinde kaplama sertliğini etkileyen en önemli parametre \% 96.44 oranla akım yoğunluğu olmuştur. Banyo sicaklı̆g 1 ise \% 3.18'lik oranla akım yoğunluğundan sonra ikinci etkili parametredir. Kaplama sertliği üzerinde diğerlerine göre daha düşük etkiye sahip parametre \% 0.07 oranla anot katot arası mesafe olarak görülmüsstür. Burada, her bir değişkenin sonuçlar üzerindeki serbestlik derecesini gösteren DF değerleriyle, kareler toplamı (SS), kareler ortalaması (MS), F değerleri ve yüzde katkı oranları (PRC) görülmektedir.

Tablo 6. Sertlik Değeri S/N oranları için Varyans analizi(ANOVA) sonuçları

\begin{tabular}{lccccc}
\hline \hline $\begin{array}{l}\text { Kaplama } \\
\text { Parametreleri }\end{array}$ & $\begin{array}{c}(\mathbf{D F}) \\
\text { Serbestlik Derecesi }\end{array}$ & $\begin{array}{c}(\mathbf{S S}) \\
\text { Kareler Top. }\end{array}$ & $\begin{array}{c}(\mathbf{M S}) \\
\text { Kareler Ort. }\end{array}$ & F-Dĕgeri & $\begin{array}{c}\text { (PRC) } \\
\text { Katkı Oranı }\end{array}$ \\
\hline \hline Anot Katot Mesafesi & 1 & 0.000000 & 0.000000 & 2.76 & $\% 0.07$ \\
\hline Akım Yoğunluğu & 2 & 0.000020 & 0.000010 & 1882.58 & $\% 96.44$ \\
\hline Banyo Sıcaklığı & 2 & 0.000001 & 0.000000 & 62.13 & $\% 3.18$ \\
\hline Hata & 12 & 0.000000 & 0.000000 & - & $\% 0.31$ \\
\hline Toplam & 17 & 0.000021 & & $\% 100.00$ \\
\hline
\end{tabular}

\subsection{Doğrulama Testi}

Taguchi tekniği ile optimizasyonda son aşama, optimum kaplama parametre seviyelerini kullanarak kaplama karakteristiklerinin gelişimini tahmin etme ve sonuçların karşılaştırılmasıdır. Taguchi metodu ile hesaplanan optimum değerler yapılan deney tasarımında yer aldığı için doğrulama deneyleri yapılmamıştır. Doğrulama deneyi yerine hesaplanan ve doğrulanan kaplama seviyelerinin deneysel sonuçları karşılaştırılması Tablo 7'de verilmiştir. Bu çalışma ile yapı çeliği üzerine elektrolitik yöntemle sert krom kaplamada, kaplama sertlik miktarının kaplama parametrelerinin değişimi ile değiştiği Taguchi deneysel tasarım ve optimizasyon metodu kullanılarak ispat edilmiştir. Taguchi optimizasyonunun kaplama çıtılarının performans karakteristiklerinin belirlenmesinde uygulanan basit ve güvenilir bir yöntem olduğu bir kez daha kanıtlanmıştır.

Tablo 7. Doğrulama deney sonuçları

\begin{tabular}{ccc}
\hline \hline $\begin{array}{c}\text { Tahmin Edilen } \\
\text { Sonuçlar }\end{array}$ & Deneysel Sonuçlar & Fark \\
\hline \hline A1B2C3 & A1B2C3 & - \\
\hline Sertlik 883.8 HV 0.1 & Sertlik 887.6 HV & \\
\hline S/N 58.9362 dB & S/N 58.9643 dB & 3.8 \\
\hline
\end{tabular}

\subsection{Kaplama Sertliği Sonuçlart}

Kaplanan numunelerin yüzey sertliği DIGIROK marka cihazda, Vickers sertlik ölçüm metoduyla ölçülmüştür. Ölçme işlemi için, piramit şeklindeki elmas uca tatbik edilecek yük $100 \mathrm{~g}$ olarak belirlenmiştir. Bu yük, 10 saniye kaplama üzerine uygulanarak piramit ucun kaplama üzerine iz bırakmas1 sağlanıp, bırakılan izlerin mesafeleri mikroskopta incelenip sertliği ölçülmüştür. Ölçümler kaplama üst noktasından başlamış ve ana malzemeye doğru her 10 mikronluk mesafelerde gerçekleştirilmiştir. Elde edilen sonuçlara ait veri grafiğgi ve değerleri Şekil 7'de verilmiştir. Sertlik diyagramı sonuçları incelendiğinde ana malzemeden, kaplamaya doğru gidildikçe sertlikte artış olduğu görülmektedir. Bunun nedeni olarak, ana malzeme içerisinde bulunan karbon atomlarının kaplama içine doğru nüfuz etmesi ve o noktalarda krom karbür çökelekleri oluşturabileceği ve kaplamanın hızlı soğumasının neden olduğu düșünülmektedir. Kaplama en uç noktasına doğru gidildikçe ise sertlik miktarında çok az bir azalma olduğu görülmektedir. 


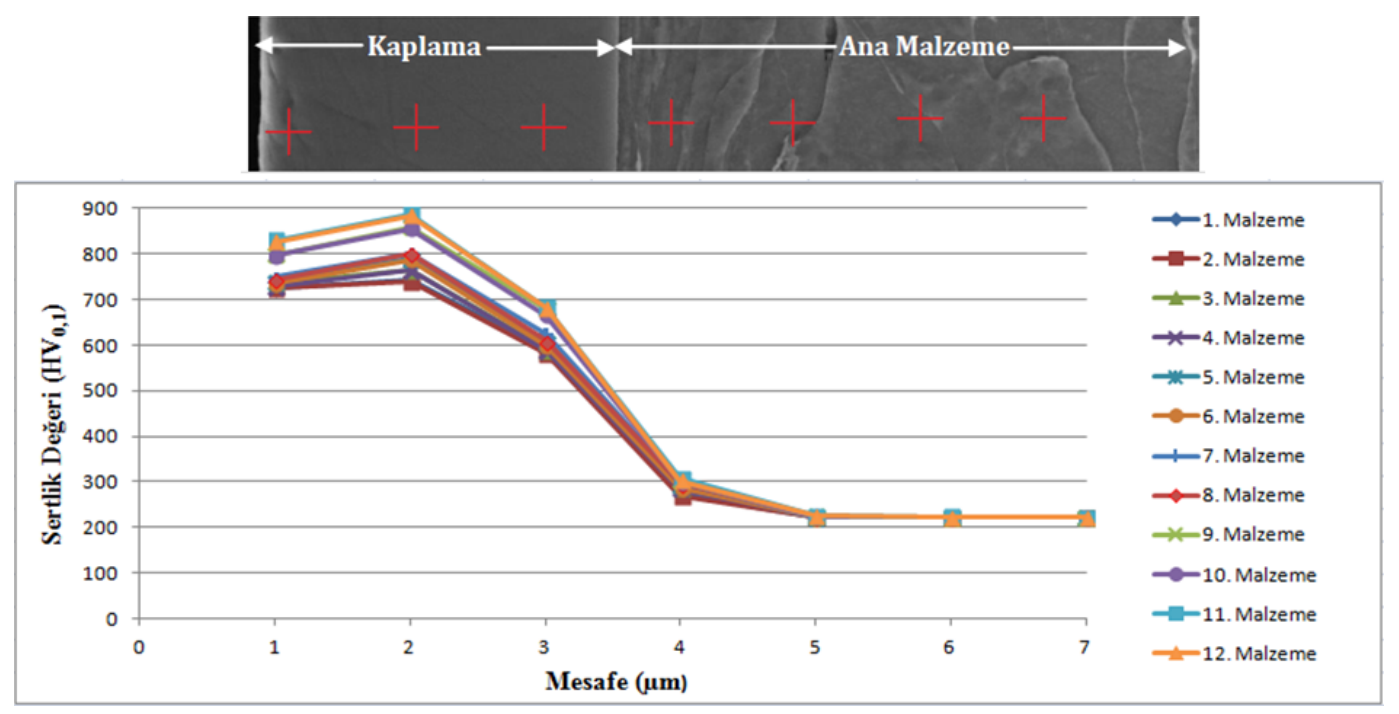

Şekil 7. Numunelerde mikro sertlik ölçümü sonuçları

\section{Sonuçlar}

Deneysel çalışmalar neticesinde elde edilen sonuçlar aşağıda sıralanmıştır.

1. Deneysel çalışmalarda, Taguchi $\mathrm{L}_{18}$ deney tasarımı ve optimizasyonu düşük karbonlu yapı çeliğinin elektrolitik sert krom kaplanması işlemi için başarılı bir şekilde uygulanmıştır.

2. En iyi kaplama sertlik değerine, $40 \mathrm{Amp} / \mathrm{dm}^{2}$ akım yoğunluğu, $60{ }^{\circ} \mathrm{C}$ sicaklık ve $100 \mathrm{~mm}$ anot-katot arası mesafede ulaşılmıştır.

3. Kaplama banyo sıcaklığının artması ile birlikte numunelerde sertlik değerinin ve aşınma değerinin arttığ 1 tespit edilmiştir.

4. ANOVA sonuçlarına göre, sertlik değeri üzerindeki en etkili parametrenin \% 96.44 oranla akım yoğunluğu olduğu \% 3.18 'lik oranla banyo sicaklığ 1 ve \% 0.07 oranla anot katot arası mesafe parametrelerinin bunu takip ettiği görülmüştür.

5. Optimum sert krom kaplama şartlarındaki sertlik değeri, sırasıyla tahmin edilen ve deneysel çalışma sonucu $883.8 \mathrm{HV}_{0.1}$ ve 887.6 $\mathrm{HV}_{0.1}$ olarak bulunmuştur.

\section{Teşekkür}

Yazarlar bu çalışmayı, 2015.07.04.392 nolu projesi ile destekleyen Düzce Üniversitesi Bilimsel Araştırma Projesi (DÜBAP) birimine teşekkür eder.

\section{Kaynaklar}

Almotairi, A., Warkentin, A. ve Farhat, Z., 2016. Mechanical damage of hard chromium coatings on 416 stainless steel. Engineering Failure Analysis, 66, 130-140.

Bolelli, G., Cannillo, V., Lusvarghi, L., ve Ricco, S., 2006. Mechanical and tribological properties of electrolytic hard chrome and HVOF-sprayed coatings, 200, 2995-3009.

Borisenko, N., Zein El Abedin, S. ve Endres, F., 2017. Electrodeposition from Ionic Liquids. Electrodeposition from Ionic Liquids. Wiley, doi: 10.1002/9783527622917.

Bozyazı, E., Ürgen, M., ve Çakır, A.F., 2004. Comparison of reciprocating wear behaviour of electrolytic hard chrome and arc-PVD CrN coatings. Wear, 256, 832-839.

Browning, M.E., 1994. ASM Handbook, Volume 5: Surface Engineering. American Society for Metals, 118p.

Chen, A., Qiu, X., Sridharan, K., Horne, W.G., Dodd, R.A., Hamdi, A.H., Conrad, J.R., 1996. Chromium plating pollution source reduction by plasma source ion implantation. Surface and Coatings Technology, 82, 305-310.

Demirsöz, R., Polat, R., Türk, A. ve Erdoğan, G., 2018. Yüksek firın granüle cürufunun sert kaplama uygulanmış ve uygulanmamış çeliklere karşı erozif aşındırma davranışının incelenmesi. Gazi Üniversitesi Mühendislik-Mimarlık Fakültesi Dergisi, 34 (1), 103-114.

Doubek, P. ve Filípek, J., 2011. Abrasive and erosive wear of technical materials. Acta Universitatis Agriculturae et Silviculturae Mendelianae Brunensis, 59, 13-21.

Emre, H.E., 2015. Taguchi Yöntemi ile Nokta Direnç Kaynaklı TWIP Çeliklerin Dayanım 
Optimizasyonu. Düzce Üniversitesi Bilim ve Teknoloji Dergisi, 4, 293-304.

Fedrizzi, L., Rossi, S., Bellei, F. ve Deflorian, F., 2002. Wear-corrosion mechanism of hard chromium coatings. Wear, 253, 1173-1181.

Gür, A.K., 2013. Investigating the Wear Behaviour of FeCrC/B4C Powder Alloys Coating Produced by Plasma Transferred Arc Weld Surfacing Using the Taguchi Method. Materials Testing, 55, 462-467.

Gür, A.K. ve Kaya, S., 2017. PTA Kaplamalarda Abrasive Aşınma Davranışının Değerlendirilmesinde; Bir Taguchi Yaklaşımı. Fırat Üniv. Müh. Bil. Dergisi, 29 (2), 195-202.

İpek, R. ve Erdoğan, M., 2006. Motor yağ1 takviyelerinin, aşınma mekanizmalarına etkisinin deneysel araştırılması. Dumlupınar Üniversitesi Fen Bilimleri Enstitüsü Dergisi, 12, 67-78.

Kahraman, F., Gençer, G.M. ve Karadeniz, S., 2013. Plazma nitrürlenmiş X40CrMoV5-1 yüksek alaşımlı çeliğin aşınma davranışının incelenmesi. Gazi Üniv. Müh. Mim. Fak. Der., 28(1), 7-14.

Kara, F., Özbek, O., Kam, M. ve Saruhan, H., 2017. AISI 4140 1slah çeliğinin tornalanmasında yüzey pürüzlülüğü ve titreşimin Taguchi metodu ile optimizasyonu, International Academic Research Congress, Ekim 2017, Antalya, Türkiye, s. 1132-1140.

Karuppasamy, S., Sivan, V., Natarajan, S., Kumaresh Babu, S.P., Duraiselvam, M. ve Dhanuskodi, R., 2018. Establishment of Wear Resistant HVOF Coatings for 50CrMo4 Chromium Molybdenum Alloy Steel as an Alternative for Hard Chrome Plating. J. Inst. Eng. India Ser. C, 100 (4), 635645.
Lausmann, G.A., 1996. Electrolytically deposited hardchrome. Surface and Coatings Technology, 86, 814-820.

Lindsay, J.H., 1999. Decorative and Hard Chromium Plating. Plating \& Surface Finishing, 1, 46-48.

Masmiati, N. ve Sarhan, A.A.D., 2015. Optimizing cutting parameters in inclined end milling for minimum surface residual stress - Taguchi approach. Measurement, 60, 267-275.

Perianu, I.A., 2016. HVOF Thermal Spray Alternative for Hard Chrome Plating Process. Advanced Materials Research, 1138, 139-146.

Rebholz, C., Ziegele, H., Leyland, A. ve Matthews, A., 1999. Structure, mechanical and tribological properties of nitrogen-containing chromium coatings prepared by reactive magnetron sputtering. Surface and Coatings Technology, 115, 222-229.

Salvador Barbato, R., Jilberto Ponce, F., Marcelo Jara, L., Jacqueline Cuevas, S. ve Rodrigo Egana, A., 2008. Study of the effect of temperature on the hardness, grain size, and yield in electrodeposition of chromium on 1045 steel. Journal of the Chilean Chemical Society, 53, 1429-1432.

Saraç, A.S., 1995. Metal Kaplama ve Elektrokimyasal Teknolojiler, Çağlayan Kitabevi, İstanbul, 83s.

Schlesinger, M. ve Paunovic, M., 2014. Modern Electroplating, Fifth Edition, Wiley. ISBN: 9780-470-16778-6, New York, 205p.

Yıldırım, M.S., Gülenç, B., Kahraman, N., Durgutlu, A., Kaya, Y. ve Çakıroğlu, R., 2019. Nokta Direnç Kaynağı ile Birleştirilen Titanyum Levhaların Çekme-Makaslama Dayanımlarının Taguchi Metoduyla Optimizasyonu. Journal of Polytechnic, 22 (2), 567-573. 